\section{Imaging Without Lenses}

Jean-Paul Revel, Caltech

In the past 10 or so years lens-less microscopies have proliferated tremendously, because they promise (and in many cases already deliver) substantial gains in performance when compared to other approaches to imaging. One of the perceived advantages is the superlative resolution which most of these techniques are (at least theoretically) capable of delivering. Another is that one can map any physical property for which there is a sufficiently sensitive detection system. Microscopists are no longer limited to imaging only regions of the sample which can be made to modulate light absorption or emission. All the simple nomograms showing what part of the spectrum to use if one wishes to see amoebae, bacteria or molecules will now have to be revised because of the advent of Scanned Probe Microscopes.

According to one of the dictionaries on my desk, a microscope is "an instrument containing one or more lenses for magnifying near objects". The other says a microscope is "an optical instrument having a magnifying lens or a combination of lenses for inspecting objects too small to be seen, or to be seen distinctly in detail, by the naked eye". So is it appropriate to call a lens-less machine a "microscope"? Should one disregard the "scholars, specialists and editors who worked to meet the essential needs of the reader, speaker, and witer who want to know the meaning of a word"? Perhaps it would be better not to offend these distinguished and devoted linguists and instead call the new machines "Scanned Probe Instruments"', abbreviated SPI. SPI would obviously to be pronounced "spy" - reminding us that with SPIs we can indeed spy on the most intimate details of materials and, perhaps, of living things as well.

The idea of lens-less microscopy seems to have originated independently many times. In his talks Michael Isaacson of Cornell, one of the pioneers in this endeavor, shows an astounding-slide listing the various independent reinventions of lens-less instruments using the near-field principle (about which more follows). Among such inventors is J.A. O'Keefe who, in 1956, wrote a theoretical paper on the "resolving power of visible light"' might be able to resolve much better than Lambda/2 if a way could be found to position an aperture in very close proximity to an object and ther scan it - the very idea of the near field microscope of today. Of course he did not realize that E.H. Synge had proposed precisely such an instrument in $1928^{10}$. Synge's concept of such a machine was slowly refined and eventually even included the use of piezo electric quart crystals as a means of scanning the sample, just as is done today. As described by McMullan $^{7}$, Synge tried out his idea on Einstein, before submitting his paper to the Philosophical Magazine. The suggestions made by the great man in his answer to this letter were incorporated in Synge's paper entitled "A suggested method for extending microscopic resolution into the ultramicroscopic region". It says something about Einstein, Synge or the changing times, that Synge was the sole author. But all of that was theoretical and, as no one read the previous literature thoroughly, the earlier work had no effect on the eventual development of the technology

In my way of seeing things, Albert Crewe ${ }^{6}$ did as much as anyone to put the lens-less microscope on the map for biologists - with his development of the Scanning Transmission Electron Microscope. In that instument, elastically and inelastically scattered electrons from each point of the sample are recorded directly by detectors placed in the image space, with no lenses in the "imaging " part of the optical train. Crewe and crew developed a very effective field emission gun which permitted scanning with a high brightness probe of very small diameter, thus achieving excellent resolution.

The Nobel committee did its bit in recognizing this new approach to microscopy by awarding their prize jointly to Binnig and Rohre ${ }^{-4}$ for their development of the Scanning Tunneling Microscope, and to Ruska for his much earlier work on the TEM. Another spectacular innovation is the Atomic Force Microscope (now called the Scanned Force Microscope) invented by Binnig while working, on sabbatical leave. with Cal Quate ${ }^{5}$. I understand Binnig formulated the concept while tired, lying in bed, and staring at ceiling cracks and wondering about ways of detection. I have looked at lots and lots of such cracks in my day ...

Up to now, at least a dozen different physical characteristics have been used to produce images in scanned probe instruments. The closest to standard light microscopy is the Near Field Scanning Optical Microscope? which we have already mentioned. It relies on light absorption or other signals such as are used in normal light microscopy. In the NSOM there is a light guide placed so close $(10 \mathrm{~nm})$ to the sample that the light beam coming from it has spread out due to diffraction, retaining nearly the same diameter as the guide. An objective placed on the image side of the sample, collects and transmits the light. The exciting part of this is that the diffraction limit is overcome by an order of magnitude. Right now the NSOM shines mostly in its ability to read (and write) nanoscale slogans and possibly allow high density data storage as suggested by Betzig et al. ${ }^{3}$, but it could be used as a nanospectrophotometer, nanofluorescence scope and who knows what else?

Finding ways to bypass the limit imposed by diffraction theory would have pleased Ernst Abbe who in 1873 published his famous "Contributions to the theory of the microscope..."1. In 1876 he expressed the thought that "one day human genius will find a way to transcend those limits which we now cannot exceed. I (Abbe) believe that the instruments which will one day allow us to observe the minutest details of the material world, may only have their name in common with the microscopes of our time." To honor Abbe and his foresight...long live the name "microscope" applied to any instrument, lensed or not, used to visualize the very small.

1. Abbe E. (1873) Archiw, Mikroskopische Anat. 9, 413.

2. Betzig E., Trautman J.K., Harris T.D., Weiner J.S. and Kostelak R.L. (1991) Seience 251, 1468.

3. Betzig E., Trautman J.K., Wolfe R., Gyorgy E.M., Finn P.L., Kryder M.H., Chang C-H, (1992) App.Phys Let 61, 142 4. Binnig G., Rohrer H., Gerber C. and Weibel E. (1992) Phys. Rew. Let. 49, 57

5. Binnig G. Quate C. and Gerber C. (1986) Phys, rew. Let. 56, 930 .

6. Crew日 A., Wall J and Langmere J. (1970) Science 168,1338 .

7. McMullan D. (1990) Proc. Roy. Mic. Soc. 25, 127

8. Giestrecht P. Schweiger H.-G. and Franke WW. (1980) Catalog of Extibtion, 2nd Int Congress on Cell Biology 9. O'Keefe J.A. (1956) J. Opt. Soc. Am. 46, 359.

10. Synge E. H. (1928) Phil. Mag. 6, 356.

\section{E.A. Fischione Instruments, Inc. - Continued}

The most sought-after device was the Automatic Twin-Jet Polisher, which after 27 years, is still an industry standard for preparing metallic TEM specimens. Gene was happy to oblige and would produce a unit in his basement workshop if the customer was patient. With a full time job and family chores, delivery times tended to be long and more than one anxious customer tried to gain a place or two in e order book through contacts with colleagues working in the Monroeville Lab. The demand >>supply "problem" grew as visitors to the newly-equipped laboratories also developed their own appetites for the electrolytic thinning devices. At one point, Basic Research management proposed setting up a "Gene Fishione Division" to meet the demand. Along with the ever-growing problems of the steel company, upper management (in its infinite wisdom) recognized that this operation would do little to meet annual billion dollar losses and Gene was allowed to continue with his officially sanctioned part-time business.

Time passed and in 1977 Gene Fischione took early retirement from USS and started producing TEM specimen preparation equipment in earnest - if it didn't interfere with something else he wanted to do. By 1986, Gene was ready for genuine semi-retirement and reduced his work week to only 40 hours. Son Paul Fischione, after a stint as an instument designer for United Technology, was ready to take over the reins of the tiny company and, seeing the potential of the TEM specimen preparation market, promptly initiated a broad program of product development activities. This soon resulted in the addition of a microprocessor-controlled dimpling grinder, and electrolytic polisher for preparing FIM/STM tips, an ultrasonic disk cutter and, recently, a computer-controlled ion mill to the companies product line.

In 1990 the "garage operation" moved into a world-class manufacturing facility, complete with $C A D$ design and computer-controlled manufacturing capabilities, and is now represented overseas in six different countries. The Fischiones, father and son, can take great pride in what they have achieved and the promising outlook for the future of their company. 